\title{
OS PRESSUPOSTOS DA ÉTICA DE PEIRCE QUE INFLUENCIARAM KARL OTTO-APEL NA CONSTRUÇÃO DA ÉTICA DO DISCURSO
}

\author{
Francisco Brandão Aguiar ${ }^{1}$ \\ Universidade Estadual do Ceará (UECE) \\ (i) https://orcid.org/0000-0002-0860-4189 \\ Luís Alexandre Dias do Carmo ${ }^{2}$ \\ Universidade Federal de Santa Catarina (UFSC) \\ Universidade Estadual do Ceará (UECE) \\ (iD) https://orcid.org/0000-0002-8550-1802
}

\begin{abstract}
RESUMO:
Neste artigo analisaremos como a filosofia de Charles Sanders Peirce influencia o pensamento de Karl-Otto Apel na elaboração da sua ética do discurso. Pretendemos mostrar que Apel compreende que Peirce elabora uma transformação da filosofia transcendental kantiana, substituindo o "eu penso" por um "eu argumento", neste viés Peirce demonstrou a existência de um acordo mútuo intersubjetivo dentro da comunidade científica. Sendo que, este acordo é mediado pela linguagem, e se dá em função da garantia da verdade das proposições. Conclui-se que Apel ver em Peirce a introdução de uma ética mínima que supera o solipsismo metódico, e se baseia na intersubjetividade, tornando possível um acordo mútuo, que mais tarde será a base para a fundamentação pragmático-transcendental da ética do discurso.
\end{abstract}

PALAVRAS-CHAVE: Pragmática Transcendental; Karl Otto-Apel; Charles Sanders Peirce; Ética do Discurso.

\section{THE PRESUPOSITIONS OF PEIRCE'S ETHICS THAT INFLUENCED KARL OTTO-}

\footnotetext{
${ }^{1}$ Mestrando em Filosofia pela Universidade Estadual do Ceará (UECE), Ceará - Brasil. Email: francisco_ba89@hotmail.com

${ }^{2}$ Em Estagio Pós-doutoral em Filosofia na Universidade Federal de Santa Catarina (UFSC), Santa Catarina - Brasil. Professor da Universidade Estadual do Ceará. Email: alexdiasdocarmo@yahoo.com.br
} 


\title{
APEL ON THE CONSTRUCTION OF THE ETHIC OF DISCOURSE
}

\begin{abstract}
:
In this article, it will be analyzed how Charles Sanders Peirce's philosophy influences Karl-Otto Apel's thinking on the elaboration of his ethic of discourse. We intend to show that Apel understands that Peirce elaborates a transformation on the Kantian transcendental philosophy, by replacing "I think" for "I argument", and in this regard, Peirce demonstrated the existence of a mutual intersubjective agreement within the scientific society. In the means that this agreement is mediated by language and is due to the guarantee of the truthfulness of the presuppositions. It is concluded that Apel sees in Peirce an introduction of a minimum ethics that overcomes the methodical solipsism, and is based on the intersubjectivity, making it possible for a mutual agreement that, later, will be the basis for the pragmatical-transcendental foundation of the ethics of discourse.
\end{abstract}

KEYWORDS: Transcendental pragmatics; Karl Otto-Apel; Charles Sanders Peirce; Ethic of Discourse.

\section{Introdução}

Neste artigo pretendemos analisar como a filosofia de Charles Sanders Peirce, influencia o pensamento de Karl-Otto Apel na construção de sua ética do discurso. Para tanto, o artigo trata-se de uma releitura apeliana dos pressupostos peirceanos, na medida em que, pretendemos mostrar como a semiótica peirceana e o conceito de comunidade ilimitada de cientistas, oferecem os elementos necessários para que Apel demonstre a superação do solipsismo metodológico ${ }^{3}$ e vislumbre o conceito de comunidade de comunicação, enquanto pressuposto inicial para a fundamentação de uma ética do discurso.

Neste sentido, não é intuito aqui apresentar o programa de fundamentação de uma ética do discurso no âmbito de uma pragmática transcendental por completo. Mas, apenas, apresentar e discutir algumas relevantes questões do pensamento de Peirce que levaram Apel a dar o pontapé inicial na construção de sua ética.

\footnotetext{
${ }^{3}$ Auto-reflexão monológica do próprio espírito. A razão do sujeito é fim em si mesma e não expõe um conhecimento objetivo do mundo, como exemplo pode se destacar o Imperativo Categórico kantiano "Age de tal maneira que a tua ação possa tornar-se uma ação universal", o sujeito é fim em sim mesmo e só depende da sua própria consciência para discernir o certo ou errado, não há necessidade do outro, nem da intersubjetividade presente nas relações humanas
}

Os pressupostos da ética de Peirce que influenciaram Karl Otto-apel na construção da ética do discurso Francisco Brandão Aguiar; Luís Alexandre Dias do Carmo.

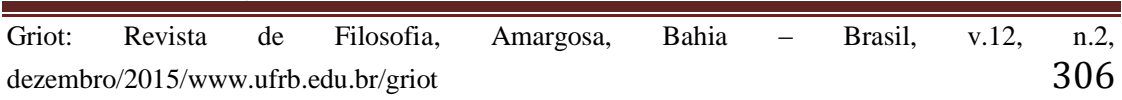


Abordaremos primeiramente a transformação semiótica da filosofia kantiana realizada por Peirce. Na visão de Apel (1985, p.189-192), Peirce teria inaugurado a semiótica tridimensional, em suas minúcias, como uma fundamentação triádica (sintaxe, semântica e pragmática) dentro da lógica da pesquisa científica. Sendo que isso ocorreu a partir de uma reconstrução da filosofia transcendental kantiana, substituindo o ponto alto da dedução transcendental de Kant, que reside na "unidade pessoal da autoconsciência" por uma "unidade semiótica" de uma interpretação consciente dos signos. Em Peirce, as condições de possibilidade e de validade do conhecimento só podem ser respondidas mediante uma relação triádica. No âmbito da ética, isto implica que o imperativo categórico kantiano dará lugar a uma "representação" intersubjetivamente válida dos objetos, por meio dos signos, a qual só pode dar-se na dimensão da interpretação dos signos.

Posteriormente mostraremos que Apel (2000, p.180) vê na filosofia Peirceana a introdução de uma ética mínima, na qual estão submetidos os cientistas no processo de investigação, como garantia de um consenso ideal que ao mesmo tempo implica uma situação real histórica, em busca da verdade do conhecer. Nesta perspectiva, o conhecimento científico é visto no sentido de uma aproximação gradual e infinita em direção à verdade, sustentado por dois aspectos que se intercruzam (mediação sígnica real; consenso ideal), formando um consenso mútuo ético.

Por último mostraremos que esse acordo mútuo intersubjetivo contraria a posição do "solipsismo metódico", na medida em que demonstra o acordo mútuo, enquanto condição de possibilidade e de validade de todo conhecimento humano. Neste sentido, a linguagem mediatiza todo sentido e toda validade. Portanto, a descoberta da mediação sígnica, enquanto instância não eliminável do processo cognitivo, liberta a filosofia do paradigma da consciência subjetiva, como ocorria em Kant, apontando a direção do paradigma da intersubjetividade que mais tarde será a base para a fundamentação da ética do discurso apeliana.

\section{Desenvolvimento}

\subsection{A transformação semiótica de Kant realizada por Peirce}

Para Apel, a retomada da questão transcendental, juntamente com as contribuições da Reviravolta Linguística, é uma possível saída contra as diversas formas de relativismo e ceticismo que marcam nossa sociedade. $\mathrm{O}$ filósofo quer encontrar um novo marco teórico, que possibilite o equacionamento dos novos problemas éticos surgidos. No entanto, tal retomada não pode ser confundida com um mero retorno à filosofia clássica, à filosofia transcendental da subjetividade de Kant. Nem tão pouco um retorno à fundamentação, com base apenas sintático semântica, da moderna lógica da ciência, enquanto instância que considera apenas a dimensão

Os pressupostos da ética de Peirce que influenciaram Karl Otto-apel na construção da ética do discurso Francisco Brandão Aguiar; Luís Alexandre Dias do Carmo.

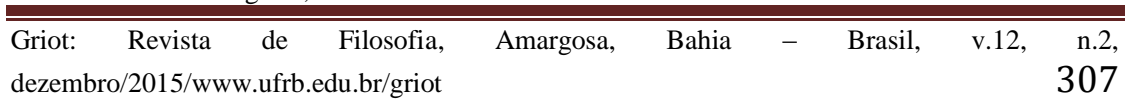


sintático-semântica do conhecimento. No entanto, tem que assumir os elementos positivos da Reviravolta Linguística. Neste sentido, Apel (2000, p.218) argumenta:

\begin{abstract}
O problema, a que nos conduziu a discussão moderna parece consistir em renovar (reformular) a pergunta Kantiana pelas condições de possibilidade e validade do conhecimento. Como uma pergunta pela possibilidade de um entendimento intersubjetivo sobre o sentido e a verdade de sentenças. Isto significaria que a crítica kantiana do conhecimento, como análise da consciência deveria trasnformar-se em uma crítica dos sentidos, enquanto análise dos signos.
\end{abstract}

Embora tenha sido Charles William Morris que introduziu a transformação semiótica da filosofia transcendental foi Charles Sanders Peirce que a desenvolveu minuciosamente. Segundo Apel (1985, p.155), Peirce teria inaugurado a semiótica tridimensional em suas minúcias, como uma fundamentação triádica (sintaxe, semântica e pragmática) dentro da lógica da pesquisa científica. Isso ocorreu a partir de uma reconstrução da filosofia transcendental kantiana. $\mathrm{O}$ ponto alto na dedução transcendental de Kant, que reside na "unidade pessoal da autoconsciência", na transformação elaborada por Peirce dará lugar a "unidade semiótica" de uma interpretação consciente dos signos. Esta nova concepção deve levar em consideração, não apenas a base sintático-semântica, como os modelos clássicos de fundamentação da ética, mas também a instância pragmática (CARMO, 2005, p.42). Assim, Peirce elabora a transformação semiótica da filosofia transcendental, substituindo o eu transcendental de Kant pela comunidade ilimitada de cientistas.

Na moderna lógica da ciência, a sintaxe e a semântica parecem ser suficientes para responder as perguntas pelas condições de possibilidade e validade do conhecimento. A sintaxe pela formalização sintática das teorias e a semântica pela relação bivalente entre teorias e fatos. Nas considerações peirceanas fica claro que esta pergunta só encontra uma resposta satisfatória, com a introdução de algo que substitua a unidade transcendental da consciência, presente na filosofia kantiana.

Para Apel (1985, p.190), o que existe em Peirce é uma transformação da filosofia transcendental de Kant, no sentido em que a unidade objetiva das representações em uma autoconsciência, como postulava o imperativo categórico, dará lugar a uma "representação" intersubjetivamente válida dos objetos por meio dos signos, a qual só pode se dar na dimensão da interpretação dos signos, ou seja, por meio de uma pragmática.

Nesta perspectiva, a universalidade das proposições das ciências é uma meta a ser alcançada no processo de investigação pela comunidade ilimitada de cientistas, ou seja, as proposições da ciência são vista como falíveis e corrigíveis, em princípio, e o conhecimento da ciência é visto no

Os pressupostos da ética de Peirce que influenciaram Karl Otto-apel na construção da ética do discurso Francisco Brandão Aguiar; Luís Alexandre Dias do Carmo.

\begin{tabular}{|c|c|c|c|c|c|c|c|}
\hline $\begin{array}{l}\text { Grio } \\
\text { deze }\end{array}$ & $\begin{array}{l}\text { Revista de } \\
/ 2015 / \text { www.ufrb }\end{array}$ & $\begin{array}{l}\text { Filosofia, } \\
\text { du.br/griot }\end{array}$ & Amargosa, & Bahia & - & Brasil, & $\begin{array}{lr}\text { v.12, } & \text { n.2, } \\
& 308\end{array}$ \\
\hline
\end{tabular}


sentido de uma aproximação gradual e infinita em direção à verdade. Sendo que tal concepção se assemelha a visão de conhecimento defendida por Karl Popper. (APEL, 1985, p.189-192).

Então, de que forma é introduzida uma comunidade ilimitada de cientistas que demarca um princípio ético transcendental? Tenta-se, em seguida, esclarecer esta questão.

\subsection{A comunidade ilimitada de cientistas como sujeito transcendental da função signica}

Peirce com seu pragmatismo traz a descoberta da dimensão pragmática da função sígnica, nesta perspectiva, o conhecimento é algo mediado por signos. Esta mediação acontece no interior de uma estrutura triádica, que não pode mais ser um mero retorno a simples relação sujeitoobjeto, como acontecia na tradição filosófica de Descartes até o Círculo de Viena. Para Apel (1985, p. 93), o pragmatismo de Peirce mostra que:

As condições de possibilidade do conhecimento não podem ser reduzidas as funções lógicas da consciência, por outro lado, também não podem atribuir-se ao objeto do conhecimento que há de ser conhecido, uma vez que, já tem que estar pressuposto. A relação cartesiana sujeito-objeto não basta para fundamentar uma antropologia do conhecimento: uma pura consciência do objeto por si só, não pode extrair do mundo nenhum sentido.

É possível perceber, então, que o que Apel está tentando introduzir a partir do pensamento de Peirce é que: a constituição individual, correspondente a possibilidade de sentido, está mediada por uma validez intersubjetiva de qualquer constituição de sentido. Neste sentido Apel (1985, p.381) fala:

\footnotetext{
Não podemos compreender argumentos, advindos da dimensão pragmática como faz o cálculo moderno (sintático semântico). Sempre temos que entendê-los, por sua vez, como pretensão de sentido e validez, que só podem explicitar-se e decidir-se em um diálogo interpessoal.
}

No modelo pragmático, a construção do processo de conhecimento é formado a partir de uma tríplice relação em que há: primeiro - o objeto real, ou seja, a coisa representada, enquanto ela é no mundo; segundo - o signo, aquilo que mediatiza o conhecimento de algo como algo; terceiro - os usuários dos signos, enquanto comunidade linguística que interpreta os sinais (CARMO, 2005, p.381).

Desta relação triádica entre os signos (objeto real, signos, usuários dos signos), Cortina (1985, p.73) afirma que Peirce extrai três

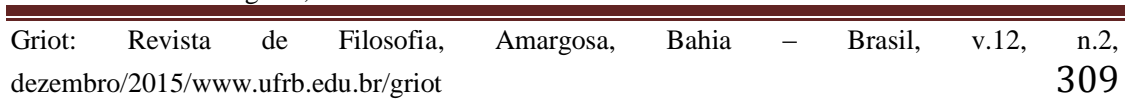


consequências para a filosofia, que se encontram na própria raiz da pragmática transcendental desenvolvida por Apel, a saber:

A primeira delas consiste em afirmar que é impossível o conhecimento de algo, como algo, sem uma mediação signica real, efetuada por signos que atuam como um veículo material. A segunda é a chave do nosso tema por que supõe a ruptura do idealismo transcendental kantiano em favor de um realismo crítico do sentido (...). A terceira consiste no fato em reconhecer sem empecilhos a necessidade de substituir a consciência transcendental kantiana por um sujeito real do conhecimento.

$\mathrm{O}$ conhecimento, então, possui uma mediação sígnica real e a existência do polo desta relação não pode ser negada. A terceira consequência mostra que, a transformação semiótica do conceito de conhecimento exige um sujeito real que faça o uso dos signos, isso seria um substituto da consciência pura, consciência esta, que era o ponto auge da filosofia kantiana.

Segundo Apel, Peirce deixa claro, ainda, que é preciso que os cientistas na disposição inicial do processo de investigação deixem de lado o egoísmo individual, em função da verdade das teorias. Neste sentido, Apel (1985, p.384) afirma:

Em Ch. Peirce é posto que a verdade - no sentido do postulado de um consenso na lógica da ciência - não pode ser alcançada por indivíduos finitos e que, portanto, a filiação de uma comunidade de argumentação dos cientistas inclui, por princípio, uma superação do egoísmo dos seres finitos: uma espécie de autorrrenuncia (selfsurrender) como exige o 'socialismo lógico'. Isso implica que o sujeito na medida em se faz membro de uma comunidade de argumentação, deve comportar-se, dai por diante, em uma relação com os demais membros (todos os seres racionais) sempre em função da superação do seu egoísmo.

Cortina (1985, p.75) afirma que, Peirce demonstra a existência de um consenso ideal como ponto supremo que garante a objetividade da verdade dentro de uma dada comunidade científica, ${ }^{4}$ ou seja, o consenso ideal funciona como um princípio regulativo, trata-se de um ideal a ser atingido, ao longo do tempo, por uma comunidade ideal de investigadores.

${ }^{4}$ CORTINA, Adela. Razón comunicativa y responsabilidad solidaria. Salamanca: Ediciones Sígueme, 1985. P. 75. "Como garantia da objetividade do conhecimento é o consenso ideal (substituto da consciência em geral) que funciona como um princípio regulativo, faz-se o uso, outra vez mais de condições ideais no seio do realismo crítico. Isso não significa um retrocesso aos postulados morais kantianos que têm por base a existência de um reino dos fins. Trata-se simplesmente de reconhecer que um realismo crítico de sentido precisa recorrer a condições ideais".

Os pressupostos da ética de Peirce que influenciaram Karl Otto-apel na construção da ética do discurso Francisco Brandão Aguiar; Luís Alexandre Dias do Carmo.

\begin{tabular}{|c|c|c|c|c|c|}
\hline $\begin{array}{l}\text { Griot: Revista de } \\
\text { dezembro/2015/www.ufrb.edu.br/griot }\end{array}$ & Amargosa, & Bahia & - & Brasil, & v.12, \\
\hline
\end{tabular}


Para Apel (1985 p.488), este comportamento humano em função da superação do egoísmo individual demarca o início de uma ética dentro da comunidade científica. $\mathrm{O}$ filósofo afirma que os pesquisadores, enquanto argumentantes devem na disposição inicial desta reconstrução ética, pressupor dois aspectos que se intercruzam: o primeiro se refere à pressuposição de uma comunidade ideal de comunicação, no sentido de uma ética fundamental, enquanto um princípio regulador, criado a partir de um acordo mútuo em prol dos objetivos da pesquisa científica. O segundo se refere à comunidade real de comunicação, em que vivem os pesquisadores, o contex to histórico real no qual estão inseridos, ou seja, refere-se ao campo da aplicabilidade, em que ocorre as pesquisa e teorias científicas criadas por "seres reais" dotados de argumentação, o que torna possível o acordo.

Desta forma, Apel vê em Peirce a introdução de uma ética mínima, na qual estão submetidos os cientistas no processo de investigação, ela funciona como um consenso ideal ilimitado que, ao mesmo tempo, implica uma situação histórica real, baseada no acordo mútuo, em busca do verdadeiro conhecimento.

Assim, Apel (1991, p.20) afirma:

É posto que não pode haver representação de algo sem uma interpretação por parte de um sujeito real, porém, a crítica do sentido exige supor uma comunidade ilimitada de cientistas, que dará conta do cognoscível em uma processo 'indefinido de conhecimento', que garantirá a objetividade da verdade do acordo nos consensos fáticos mediante um consenso ideal, que funciona como uma ideia regulativa.

A comunidade ilimitada de cientistas deve busca realizar o ideal no real, implica uma noção de conhecimento como um processo de interpretação real e histórico, pressupõe que reina um acordo entre os investigadores, que são os intérpretes dos signos, que entram em um acordo sobre os métodos de experimentação.

O que Apel mostra é que o que existe, na verdade, em Peirce é um acordo mútuo sobre o sentido das proposições e que este acordo pressupõe uma validez intersubjetiva. A linguagem neste viés é o veículo que mediatiza esse sentido, tornando possível esta intersubjetividade e, posteriormente, tornando possível o acordo mútuo.

\subsection{A superação do solipsismo metodológico e a introdução do conceito de comunidade ilimitada de comunicação}

Cortina (Apud CARMO, 2005, p.48) afirma que a transformação semiótica da filosofia elaborada por Peirce impõe uma série de questionamentos quanto à noção de "solipsismo metódico". Quanto a esta noção, Apel argumenta que toda filosofia desenvolvida ao longo da

Os pressupostos da ética de Peirce que influenciaram Karl Otto-apel na construção da ética do discurso Francisco Brandão Aguiar; Luís Alexandre Dias do Carmo.

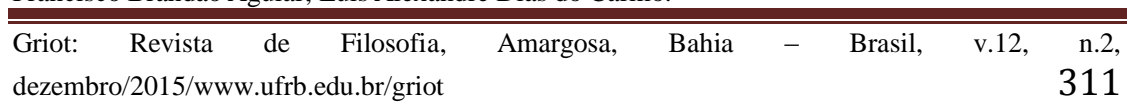


modernidade desde Descartes, passando por Locke, Kant e Husserl, até o neopositivismo parte da pressuposição de que é possível um indivíduo solitário ser capaz de conhecer algo como algo, por meio da relação sujeitoobjeto, desta forma cultivando ciência. Segundo o filósofo, isso ocorre devido ao desconhecimento por parte de todos eles de que o conhecimento baseado na observação, que ocorre na relação sujeito-objeto pressupõe sempre um acordo sobre o sentido. Apel (1998, p.20) argumenta,

Com efeito, a filosofia da consciência no sentido de Descartes, Kant e Husserl, é uma filosofia solipsista, na medida em que, obriga os outros (eus) sujeitos, a partir da consciência do próprio eu. Sem descobrir a intersubjetividade mediante reflexão transcendental.

Quem argumenta levanta algo em direção àqueles a quem fala, tendo a pretensão de que o que é proferido faça sentido. Assim, todo ato de fala, enquanto utilização de sentenças em uma situação de comunicação tem uma forma dupla: dizer algo a alguém é estabelecer, ao mesmo tempo, uma relação intersubjetiva (parte performativa), e um postulado de pretensão de validade para aquilo que é dito (parte proposicional).

Herrero (2000, p.166) argumenta que a descoberta da linguagem enquanto mediadora de toda relação entre sujeito e objeto, inevitavelmente presente em toda comunicação humana, implica um "entendimento mútuo" sobre o sentido de todas as palavras usadas. Esse acordo mútuo intersubjetivo contraria a posição do "solipsismo metódico", na medida em que demonstra o acordo mútuo intersubjetivo, enquanto condição de possibilidade e de validade de todo conhecimento humano. Neste sentido, a linguagem mediatiza todo sentido e validade.

Houve, portanto certa dificuldade por parte do "solipsismo metódico" em tematizar o problema da intersubjetividade do conhecimento. Isso ocorre devido ao fato destes filósofos verem a linguagem apenas como um instrumento de comunicação do significado. Essa concepção teria levado a uma cegueira, quanto ao papel efetivo da intersubjetividade, enquanto mediação para constituição e validade do conhecimento.

Assim, para Apel (1998, p.19):

A grande interrogação agora é perguntar por a possibilidade de um acordo intersubjetivo sobre o sentido e a verdade dos enunciados, de modo que, o "idealismo transcendental de Kant dê um passo mais adiante em direção a um realismo crítico do sentido.

Apel (2000, p.218) reconhece uma mudança de polo do paradigma da subjetividade para o paradigma da intersubjetividade. A transformação semiótica da filosofia transcendental elaborada por Peirce, com a descoberta da mediação signica, enquanto instância ineliminável do processo cognitivo,

Os pressupostos da ética de Peirce que influenciaram Karl Otto-apel na construção da ética do discurso Francisco Brandão Aguiar; Luís Alexandre Dias do Carmo.

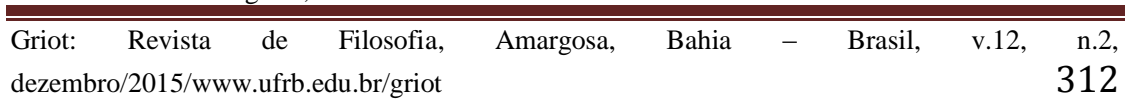


liberta a filosofia do paradigma da consciência subjetiva, apontando a direção do paradigma da intersubjetividade. A introdução da dimensão pragmática dos signos marca a superação da concepção solipsista da teoria tradicional do conhecimento.

Segundo Apel (Apud ARRUDA, 2002, p.108-109), a ética kantiana, com a introdução do imperativo categórico é uma das maiores defensoras do solipsismo metódico. Porém, a transformação da filosofia transcendental de Kant possui características, que se distanciam de suas raízes tradicionais, ela tem sobre o idealismo kantiano uma dupla vantagem. A saber:

1) Ela substitui a distinção metafísica entre coisa em si e fenômeno pela noção de um progresso, in thelongrun, no sentido de um acordo intersubjetivo, ou seja, pela ideia de uma aproximação, de verdade, que é um ideal regulador pressuposto na comunidade de comunicação.

2) Não é mais preciso supor o sujeito do conhecimento como um limite do mundo fenomênico, ao contrário, o sujeito é uma comunidade real de comunicação e tanto o consenso cognitivo, quanto o acordo sobre regras práticas, embora ideias reguladoras estejam sempre antecipadas contrafaticamente e tem que poder realizar por princípio, na comunidade real de comunicação.

Percebe-se, então, que em Peirce, a possível objetividade defendida pela ciência se dá no processo histórico do acordo mútuo na comunidade de cientista. Este consenso que sustentaria a garantia da objetividade do conhecimento é posto no lugar da consciência geral de Kant.

Porém, Apel (Apud CENCI, p.44-55) argumenta que a ética peirceana do acordo mútuo está limitada a comunidade de cientistas, assim, é preciso expandir o pragmatismo semiótico. Tal acordo não deve permanecer associado, primariamente, ao conhecimento de estados de coisas comprováveis experimentalmente. Desta forma, Apel irá introduzir o conceito de comunidade de comunicação, como forma de expandir a ética da ciência para uma ética da humanidade, em que se considere abranger todas as atividades humanas, uma vez que o conceito de comunicação abrange todos os sujeitos capazes de comunicação linguística e argumentação.

Apel (1998, p.21) argumenta que:

A comunidade ilimitada, que era na filosofia de Peirce a comunidade de investigadores, deve se transformar em uma pragmática transcendental e em uma comunidade ideal de argumentantes, que não somente é pressuposto pragmático do discurso teórico, preocupado com a verdade dos enunciados, como também do discurso prático, que se pergunta pela correção das normas da ação. No qual nos permite superar a

Os pressupostos da ética de Peirce que influenciaram Karl Otto-apel na construção da ética do discurso -

Francisco Brandão Aguiar; Luís Alexandre Dias do Carmo.

\begin{tabular}{|c|c|c|c|c|c|c|c|}
\hline $\begin{array}{l}\text { Grio } \\
\text { deze }\end{array}$ & $\begin{array}{l}\text { Revista de } \\
\text { /2015/www.ufrb. }\end{array}$ & $\begin{array}{r}\text { Filosofia, } \\
\text { du.br/griot }\end{array}$ & Amargosa, & Bahia & - & Brasil, & $\begin{array}{r}\text { v.12, } \\
\\
313\end{array}$ \\
\hline
\end{tabular}




\begin{abstract}
separação kantiana entre o ponto supremo da percepção transcendental - o "eu penso" num prático - e um "eu atuo" para os quais não pode haver, dedução transcendental no mesmo sentido da dedução das categorias no âmbito teórico. O sujeito transcendental kantiano é, pois, subtituido por um "nós argumentamos", por uma intersubjetividade que representa "o ponto supremo da reflexão".
\end{abstract}

O cientista precisa reconhecer a igualdade de direitos dentro de sua comunidade, assim tem que estar submetido desde já, a uma norma moral para poder alcançar um dado objetivo da ciência. Apel (1998, p.56) nota, então, uma vertente moral como norma, mesmo dentro de uma comunidade científica, e introduz o conceito de comunidade de comunicação, em substituição à comunidade de investigação. Dessa forma, a norma básica é estruturada a partir da ideia de que o discurso argumentativo pressupõe condições ou regras ideais de simetria entre os argumentantes. As condições de argumentação buscam uma reciprocidade generalizada, em que todos os envolvidos tenham iguais direitos nas ações, e até mesmo para quem não está envolvido no discurso das decisões. A reciprocidade traz, ainda, como reivindicação considerar os demais sujeitos como fins em si mesmo, procurando não mentir ou enganar, assim as ações não devem ser apenas de modo estratégico e a omissão de argumentos também não deve existir. Neste sentido, Apel (1998, p.56) enfatiza "a obrigatoriedade de serem consideradas todas as necessidades humanas, mesmo as virtuais e de virtuais membros da argumentação.”. Ainda neste sentido, as necessidades humanas devem ser reconhecidas na medida, em que podem ser expressas pela linguagem interpessoalmente, assim, o discurso argumentativo contém um $a$ priori racional de fundamentação para o princípio da ética.

Pode-se, então, perceber em Apel que a linguagem pode ser entendida como esse novo marco teórico que o filósofo buscava para o equacionamento dos problemas éticos, que surgiram a partir da modernidade, uma vez que a descoberta da linguagem, enquanto médium intransponível de toda relação teórica e prática media todo sentido de toda e qualquer afirmação, podendo possibilitar o acordo mútuo. Neste sentido, Apel percebe a necessidade de mostrar como o paradigma clássico do logos da linguagem cedeu lugar ao novo paradigma da relevância do logos, no âmbito da fundamentação de uma ética discursiva. É o que se verá em seguida.

\title{
3. Conclusão
}

Conclui-se que Apel recebe influência direta da filosofia peirceana, mais precisamente, da transformação semiótica da filosofia transcendental kantiana realizada por Peirce. Neste sentido, ele mostra que Peirce elaborou uma reconstrução da filosofia de Kant, substituindo o ponto alto da dedução

Os pressupostos da ética de Peirce que influenciaram Karl Otto-apel na construção da ética do discurso Francisco Brandão Aguiar; Luís Alexandre Dias do Carmo.

\begin{tabular}{|c|c|c|c|c|c|}
\hline $\begin{array}{l}\text { Griot: Revista de } \\
\text { dezembro/2015/www.ufrb.edu.br/griot }\end{array}$ & Amargosa, & Bahia & - & Brasil, & v.12, \\
\hline
\end{tabular}


transcendental na filosofia kantiana, que residia na "unidade pessoal da autoconsciência" por uma "unidade semiótica" de uma interpretação consciente dos signos.

No âmbito da ética, isto implica que o imperativo categórico kantiano deu lugar a uma intersubjetividade mediada pela linguagem. Esta intersubjetividade presente na comunidade ilimitada de cientistas faz Apel vislumbrar uma ética mínima dentro da filosofia peirceana, isto é, Apel percebe um acordo mútuo intersubjetivo em função da verdade das proposições. Este acordo mútuo contraria a posição do "solipsismo metódico", libertando a filosofia do paradigma da consciência subjetiva, como ocorria em Kant, apontando na direção do paradigma da intersubjetividade que mais tarde será a base para a fundamentação da ética do discurso apeliana.

\section{Referências bibliográficas}

APEL. Karl-Otto. Cientificismo ou hermenêutica transcendental? In: Transformação da filosofia. São Paulo: Loyola, 2000.

1985. . La transformación de La filosofia. Tomo II. Tauros. Madri, Teoria de la verdad y ética del discurso: Introducción de Adela Cortina Paidós/ I.C.E- U. A. B. Barcelona - Buenos Aires - México. Ediciones PaidósC.E de la Universidad Autónoma de Barcelona. Edición, 1991/Reimpresión, 1998. . Transformação da filosofia. São Paulo: Loyola, 2000. P.180.

ARRUDA, José Maria. Filosofía contemporânea: analítica, hermenéutica, pragmática. Fortaleza: Demócrito rocha, 2002.

CARMO, Jorge Antônio dias do. A universalização como critério moral: Kant e Apel. Fortaleza: UFC, 2005.

CENCI, A. V. A Controvérsia entre Habermas e Apel acerca da relação entre moral e razão prática na ética do discurso. 2009. 218 f.Tese (Doutorado em Filosofia) - Departamento de Filosofia.Universidade de São Paulo, Campinas, 2006.

CORTINA, Adela. Razon comunicativa y responsabilidad solidária. Salamanca: Ediciones Sígueme, 1985.

HERRERO, F. Javier. Ética do discurso. In: OLIVEIRA, Manfredo a de. Correntes fundamentais da ética contemporânea. Rio de Janeiro Vozes, 2000.

OLIVEIRA, Manfredo a de. Correntes fundamentais da ética contemporânea. Rio de Janeiro Vozes: 2000.

\section{Contribuição dos autores:}

Os autores Francisco Brandão Aguiar e Luís Alexandre Dias do Carmo participaram conjuntamente da discussão, problematização, revisão e redação do artigo. Ambos aprovaram a versão final do texto

Os pressupostos da ética de Peirce que influenciaram Karl Otto-apel na construção da ética do discurso Francisco Brandão Aguiar; Luís Alexandre Dias do Carmo.

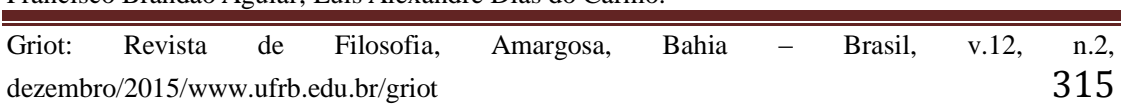

